\title{
Digital Deliberation Boards and Signaling System in South Central Railways
}

\author{
Razia Sultana, \\ Student, \\ Gudlavalleru Engineering \\ College, \\ Gudlavalleru, Krishna District, \\ Andhra Pradesh, India.
}

\author{
G. Rama krishna \\ Assistant Professor \\ Gudlavalleru Engineering \\ College \\ Gudlavalleru, Krishna District, \\ Andhra Pradesh, India.
}

\author{
V. Samson Deva Kumar, \\ Project manager, \\ Software development \& \\ training center, \\ South central railways (wwo).
}

\begin{abstract}
In Indian Railways, accidents have been caused due to failure of misleading the train with different speeds resulting in accidents and accidents due to invisibility of signal at the signal post. This paper is describes to prevent train accidents due to misleading of train speed and invisibility of signals at the signal post near to the station. To overcome this problems, according to the change in distances the speed at which the loco pilot has to drive are displayed on the LCD. In signaling system the signals which are not visible to the loco pilot because of fog or smoke are displayed in LCD display which is transmitted from control room of the station by using RF module.
\end{abstract}

\section{Keywords}

Loco pilot, RF Module, LCD.

\section{INTRODUCTION}

In Indian Railways, accidents have been caused due to failure misleading the train with different speeds resulting in accidents and accidents due to invisibility of signal at the signal post. Railways are providing a hard copy to the loco pilot which consists of speed limit's at different distances.

In the present system loco pilots are being served with paper caution order to observe the various speed restrictions in his entire journey. There should be a chance of accidents in conditions like if the caution paper is lost or if the paper is damaged due to some reasons. So, to overcome these problems an advanced embedded technology [1] i.e., digitalizing [6] the caution paper using LCD display in the train.The loco pilot should maintain the speed of the train using RF communication automatically. In our project; we use IR sensors, relays, motor to represent the train engine, and buzzer to alert the driver about the emergency caution. The loco pilot can help the passengers to reach their destination safely. The entire function of our project can be maintained by the microcontroller we used. The ATMEL 89S52 [2,4] is chosen as it is advanced and ease to control the functions. The block diagram consists of different components interfacing to a microcontroller. The block diagram is shown in Figure 1. The various components in the block diagram are mentioned below: according to the display. Signaling switch is present in the control room. The station master will select the signal (red, green, yellow) which is shown at the signal post. As there are some limitations regarding maintenance of hard copy. If it is lost or damaged the loco pilot has a chance of misleading the train with different speeds resulting in accidents. The speeds vary from one area to another area to another area and the deliberation boards indicate this information. The trains may not maintain the speed at specified areas, due to its momentum or the driver's overlook leading to train accidents. The loco pilot should maintain the speeds continuously at different distances without fail by using RF communication and at particular areas the speed is predefined.

To avoid such incidents, has proposed the idea of digital deliberation boards and signaling system. This project contains no. of RF [1,2,3, 4] modules .The distance travelled by the train is noted and when the train crosses a particular distance, a message is indicated to the driver of the train on an LCD [4] display which are predefined. If any caution occurs the message is also displayed on the LCD is possible with the help of RF modules .This message will be sent from the control room to RF modules. In signaling system the signals which are not visible to the loco pilot because of fog or smoke are displayed in LCD display which is transmitted from control room of the station by using RF module.

\section{SYSTEM DESIGN MODEL} \subsection{Hardware Design Implementation}

To indicate the loco pilot about the speeds. The program to microcontroller about all the ordinary speeds should be maintained. The temporary cautions and signals are indicated. 


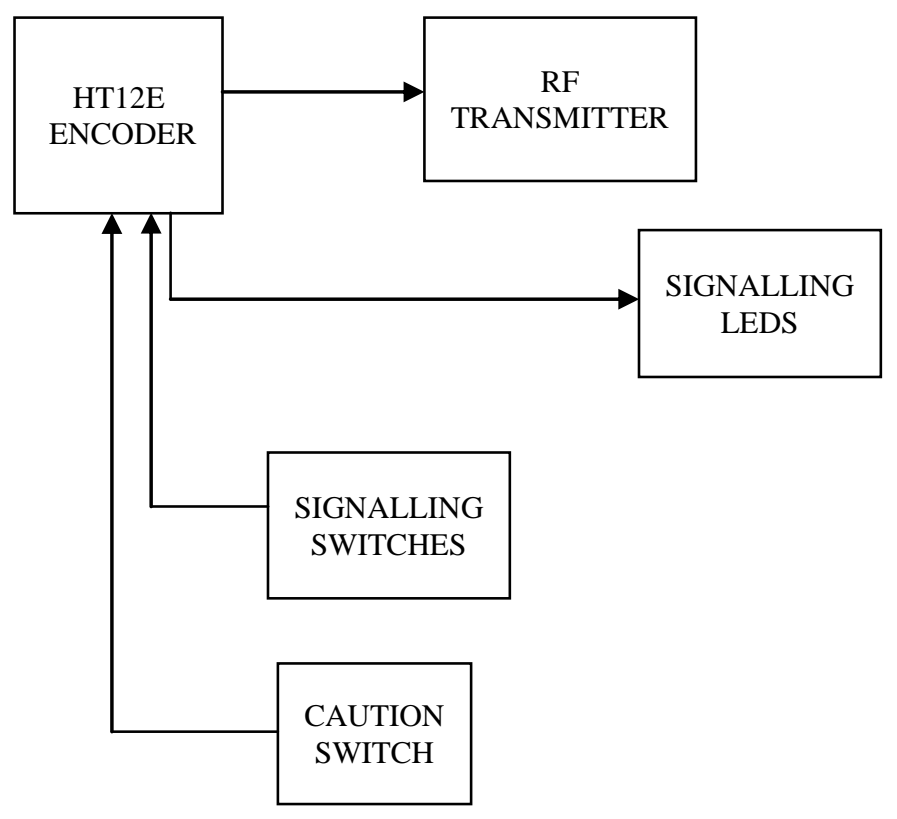

Figure 1: Block Diagram of transmitter section

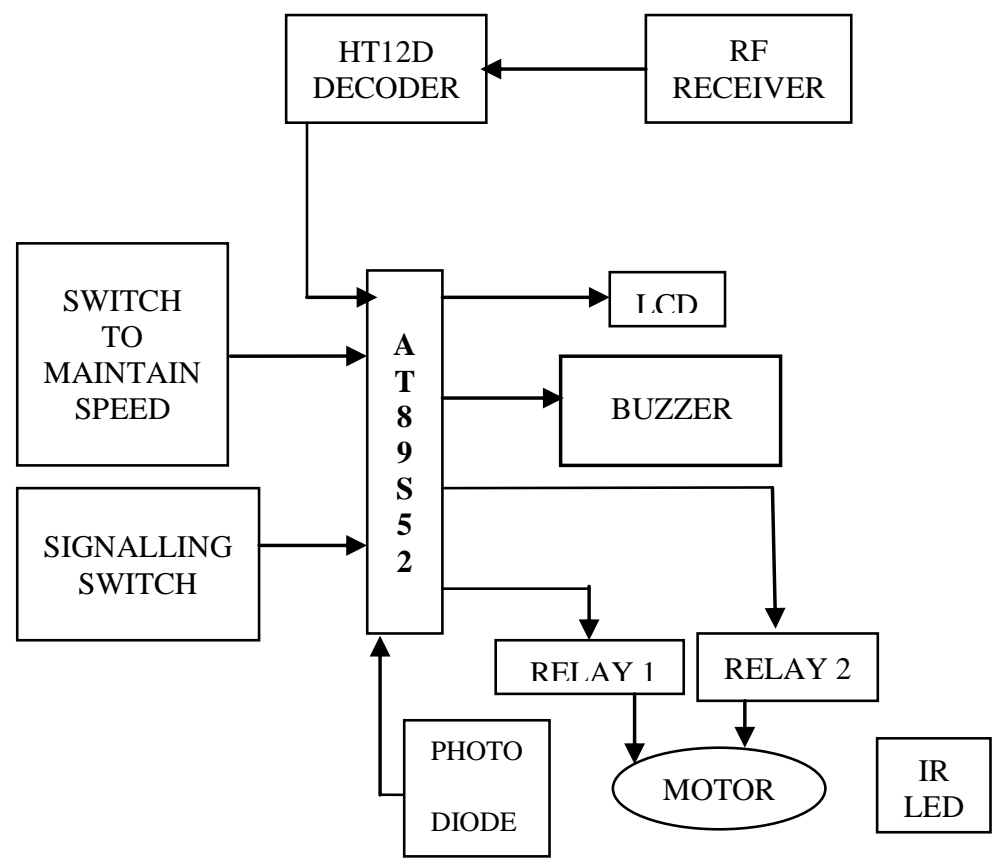

Figure 2: Block Diagram of receiver section

Microcontroller Unit: The AT89S52 is a low-power, high performance 8-bit CMOS microcontroller with $8 \mathrm{~K}$ bytes of insystem programmable Flash memory. The device is manufactured using Atmel's high-density nonvolatile memory technology and is compatible with the industry standard $80 \mathrm{C} 51$ and 80C52 instruction set and pin out. The on-chip Flash allows the program memory to be reprogrammed insystem or by a conventional nonvolatile memory programmer. By combining a versatile 8-bit CPU with in-system programmable Flash on a monolithic chip, the Atmel AT89S52 is a powerful microcontroller which provides a highly-flexible and cost-effective solution to many embedded control applications.

Power Supply: The input to the circuit is applied from the regulated power supply. The microcontroller voltage is of $5 \mathrm{~V}$. The A.C. input i.e., $230 \mathrm{~V}$ from the mains supply is step down by the transformer to $12 \mathrm{~V}$ and is fed to a rectifier. The output of the rectifier is a pulsating D.C voltage. So in order to get a pure D.C voltage, the output voltage from the rectifier is fed to a filter to remove any A.C components present even after rectification. Now, D.C voltage is given to a voltage regulator to obtain a pure constant dc voltage. We are using an IC 7805 as voltage regulator to get a $5 \mathrm{~V}$ output Voltage.

Liquid Crystal Display (LCD): LCD (Liquid Crystal Display) screen is an electronic display module and find a wide range of applications. A 16x2 LCD means it can display 16 characters per line and there are 2 lines. In this JHD 16x2A LCD each character is displayed in $5 \times 7$ pixel matrix. This LCD has two registers, namely, data and command. The command register stores the command instructions given to the LCD. A command instruction is given to LCD to do a predefined task like clearing its screen, initializing it, setting the cursor position, controlling display etc. The data register stores the data to be displayed on the LCD. The LCD used is the 4-bit nibble in which 4 data lines are used to transmit 8-bit of data. The higher data lines send the data when enable is high and the lower data lines are masked. The data in the lower data lines are left shifted 4 times so that it is placed in the higher data lines and same process is repeated.

The LCD display is connected to the output port of micro controller to display the cyclic operations of deliberation boards and to display signals.

\section{$\begin{array}{llllllllllllll}\text { V } & \text { V } & \text { V } & \text { R } & \text { R } & \text { E } & \text { D } & \text { D } & \text { D } & \text { D } & \text { D } & \text { D } & \text { D } & \text { D } \\ \text { S } & \text { D } & \text { E } & \text { S } & \text { W } & & \text { O } & \text { 1 } & \text { 2 } & \text { 3 } & \text { 4 } & \text { 5 } & \text { 6 } & 7\end{array}$

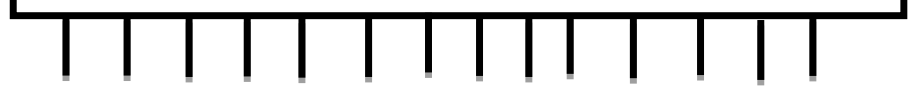

Figure 3: Schematic diagram of $16 \times 2$ LCD

LED: Light-emitting diodes are elements for light signalization in electronics. They are manufactured in different colors, shapes and sizes. For their low consumption low price and simple to use. They perform similar to common diodes with the difference that they emit light when current flows through them. Light emitting diodes (LEDs) are semiconductor light sources. Based on semiconductor diode, LEDs emit photons when electrons recombine with holes on 
forward biasing. The forward voltage of LED $(1.7 \mathrm{~V}-2.2 \mathrm{~V})$ is lower than the voltage supplied $(5 \mathrm{~V})$ to drive it in a circuit. Using an LED with 5V supply would burn it because a high current would destroy its $\mathrm{p}-\mathrm{n}$ gate. Therefore a current limiting resistor is used in series with LED. The LED is interfaced to the output port of micro controller as the first indication to alert the driver.

Buzzer: Buzzer is an audio signaling device, which may be mechanical, electronic or electro-mechanical that sounds a warning of continuous or intermittent sound. It is compact and produces high sound pressure levels with minimal power consumption. The range of operating voltages is from 1 to $30 \mathrm{~V}$ whilst sound output may be as high as $75 \mathrm{~dB}$ at $1 \mathrm{~m}$. Normally, buzzers operate a buzzing noise in the frequency range 300 to $500 \mathrm{~Hz}$. This is used to alert the driver. The buzzer is connected to output port as a second indication to driver.

Relay: A relay is an electrically controllable switch widely used in industrial controls, automobiles and appliances. A relay is able to control an output circuit of higher power than the input circuit. Relays are devices which allow low power circuits to switch a relatively high Voltage/Current ON/OFF. For a relay to operate a suitable pull-in \& holding current should be passed through its coil. Mostly used relay coils are designed to operate from a particular voltage often its $5 \mathrm{~V}$ or $12 \mathrm{~V}$. The relay used is 5-pin relay to drive motor as an indication for movement of train.

DC Motor: DC (direct current) motors convert electrical pulses to mechanical movement. Maximum speed of DC motor is indicated in RPM. The RPM is reduced when moving a load and it decreases as the load increases. The permanent magnet DC motor can be modeled as a device that produces torque proportional to the current flowing through it. It also produced a voltage proportional to the rotational velocity. The RPM of a motor is proportional to the voltage across its terminals. The motor will spin up in speed until the generator portion of the motor model matches the supply voltage. At that point no current will flow into the motor and it will produce zero torque. But, there is some amount of friction, so there will be some amount of torque required to spin the motor, thus some amount of current needed. This current causes a voltage drop across the small series resistance in motor model. This voltage drop takes away from supply voltage and causes the motor to spin a bit slower than the supply voltage would indicate.

RF module: The RF module, as the name suggests, operates at Radio Frequency. In this RF system, the digital data is represented as variations in the amplitude of carrier wave. This kind of modulation is known as Amplitude Shift Keying (ASK).Transmission through RF is better than IR (infrared) because of many reasons. Firstly, signals through RF can travel through larger distances by ASK modulation making it suitable for long range applications. Also, while IR mostly operates in line-of-sight mode, RF signals can travel even when there is an obstruction between transmitter \& receiver. Next, RF transmission is more reliable and strong than IR transmission. RF communication uses a particular frequency unlike IR signals which are affected by other IR emitting sources. The RF module consists of an RF Transmitter and an RF Receiver. The transmitter/receiver (TX/Rx) pair operates at a frequency of $434 \mathrm{MHz} \mathrm{RF}$ transmitter receives serial data and transmits it wirelessly through RF. The transmission occurs at the rate of $1 \mathrm{Kbps}-10 \mathrm{Kbps}$. The transmitted data is received by an RF receiver operating at the same frequency as that of the transmitter.
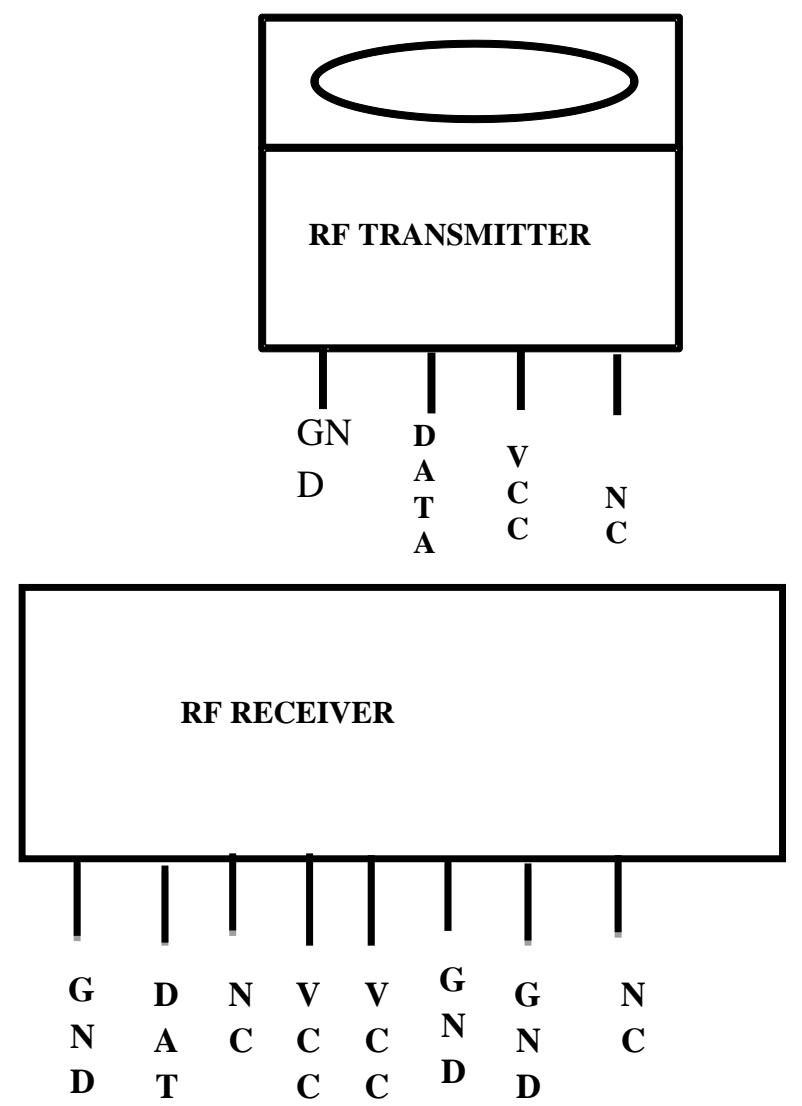

Figure 4: RF Module.

The RF transmitter is present at the signal posts and at the control room. The RF receiver is present in the train. Here one $\mathrm{RF}$ receiver and $4 \mathrm{RF}$ transmitters are used.3 RF transmitters are present at the 3 signal posts to send the signals, $1 \mathrm{RF}$ transmitter is present at the control room to send the message of caution.

HT12E ENCODER: In HT12E, HT means HOLTEK, 12 is 8 -address lines and 4-data lines, E is encoder. The HT $12 \mathrm{E}$ Encoder ICs are series of CMOS LSIs for Remote Control system applications. It is capable of Encoding 12 bit of information which consists of $\mathrm{N}$ address bits and 12-N data bits. Each address/data input is externally trinity programmable if bonded out.

HT12D DECODER: In HT12D, HT means HOLTEK, 12 is 8 -address lines and 4-data lines, D is decoder The HT 12D ICs are series of CMOS LSIs for remote control system applications. These ICs are paired with each other. For proper operation a pair of encoder/decoder with the same number of 
address and data format should be selected. The Decoder receive the serial address and data from its corresponding decoder, transmitted by a carrier using an Retransmission medium and gives output to the output pins after processing the data.

\subsection{Working Of The Design}

When the engine is started, the motor starts running which has a wheel at front. Few number of wheel rotations are consider as few kilometers the distance travelled. The counting of the wheel rotation is done by passing the IR rays from the IR LED through the hole of the wheel. If it passes through the hole once, then it has one rotation. The IR rays are fallen on a photo diode which comes from the hole of the wheel. It counts the rays and Passes it to the AT89S52.As the rotations are completed the speed will be changed. If the rotations are not completed then the same speed is displayed. If any problem occurs on the track or bride repair is going on then the station master will send the message to the loco pilot by using RF transmitter which is received by the Receiver and interrupt is made to the AT89S52 and it is displayed on the LCD.By viewing the display, the loco pilot will press the speed switch. If high speed is required $+12 \mathrm{v}$ relay is on and passes it to the motor and if low speed is required $+5 \mathrm{v}$ relay is on and passes it to the motor. So that, the speed is changed. The Signaling switches are present at the control room. He will switch on the signaling switch and the corresponding led (Red, Green, Yellow) is glow and message to the loco pilot is transferred with the help of RF module which are displayed on the LCD.

\subsection{Software Design Implemenattion}

For the operation purpose, the user application instructions are written programming code by using embedded c. The application program is compiled by using KEIL-C compiler and converts the source file into .hex file. For the dumping purpose, we use micro flash programmer. Here the program is dumped in the microcontroller ROM memory location and the software implementation of the circuit done by using the PROTEUS TOOL. Proteus is software for microprocessor or micro controller simulation, schematic capture, and printed circuit board (PCB) design. In proteus, designing is done by collecting the components from the library. By drag and drop the components can be placed. The code is dumped into the controller and output is verified as shown in the figure 5 .

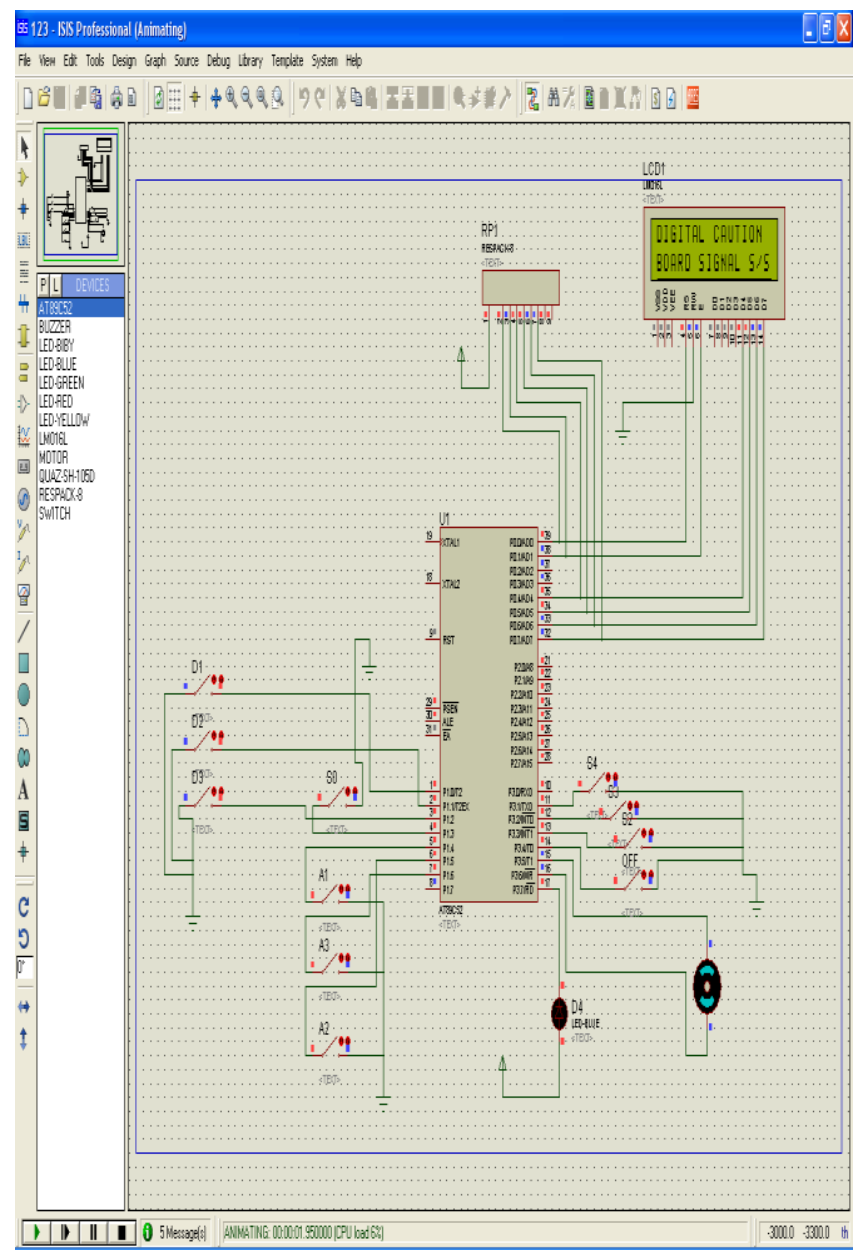

Figure 5: circuit design of working model.

\section{EXPERIMENTAL RESULTS}

This paper gives a different way of approaching the problem. The proposed system is gives the maintenance of speed levels at various locations and signal is visible to the loco pilot in thetrain which is send by RF module. By using the flow chart in figure 5 the source code is developed. The source code is written in embedded C language and is tested on Proteus 7.2 platform. The hardware implementation of the digital deliberation boards and signaling system is shown in figure 7 . 


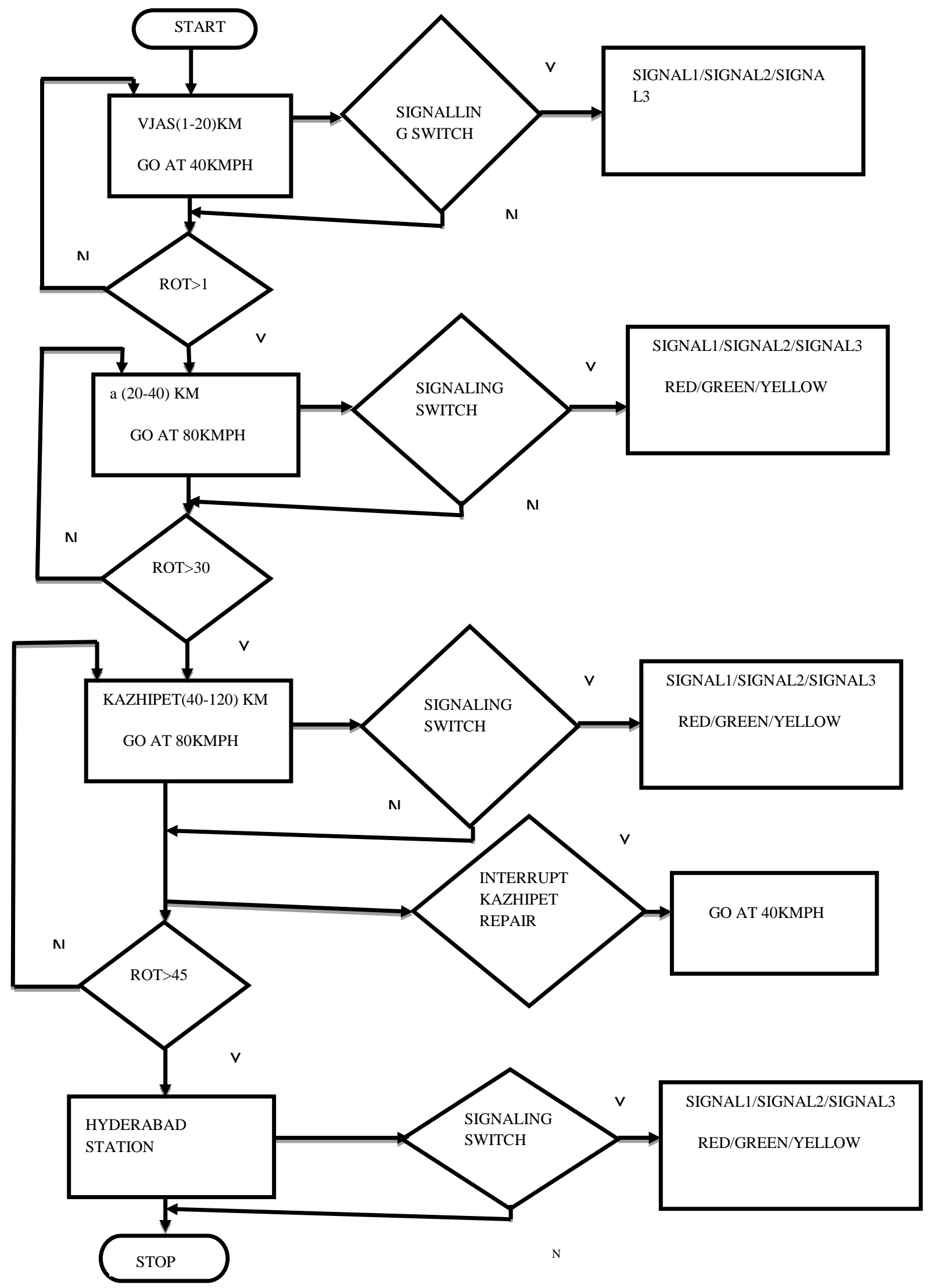

Figure 6: Flow Chart of the System 


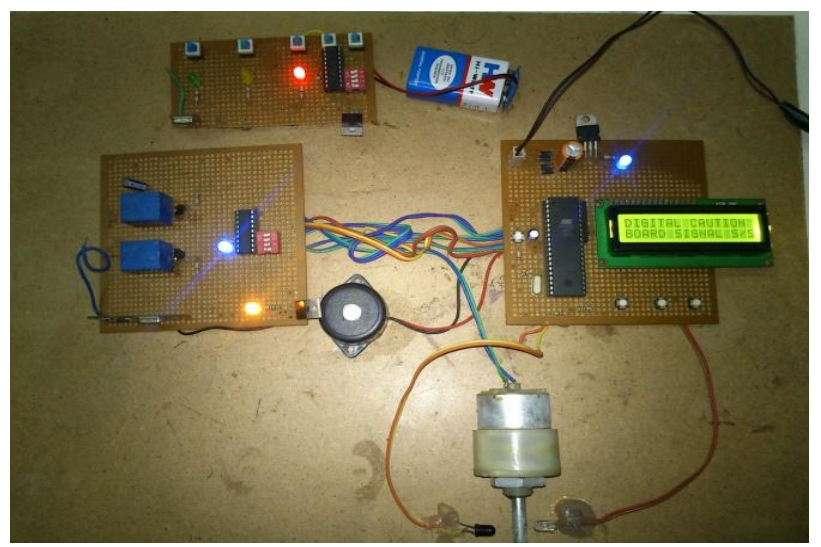

Figure 7: Hardware Implementation of Digital deliberation board and signaling system

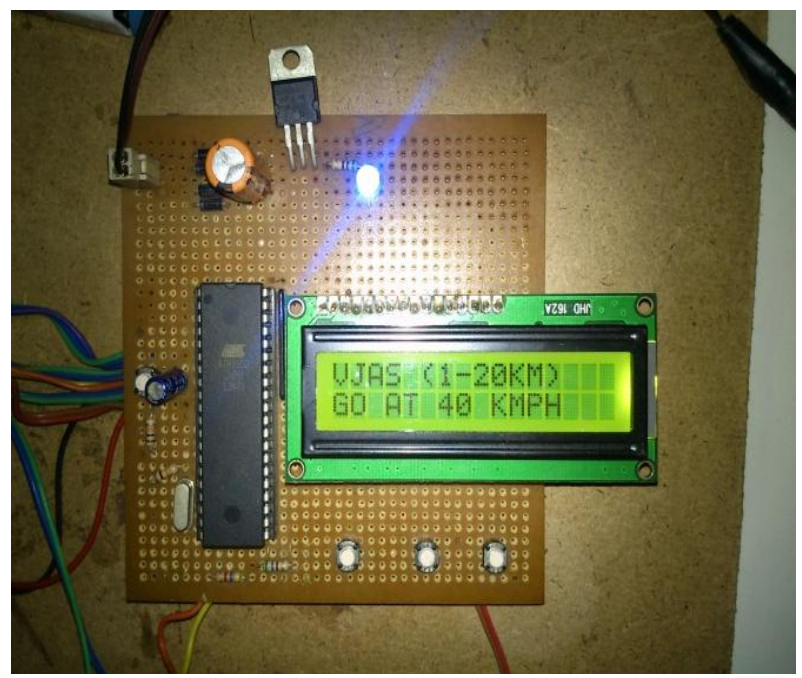

Figure 8: Display of station with speed level when engine is started.

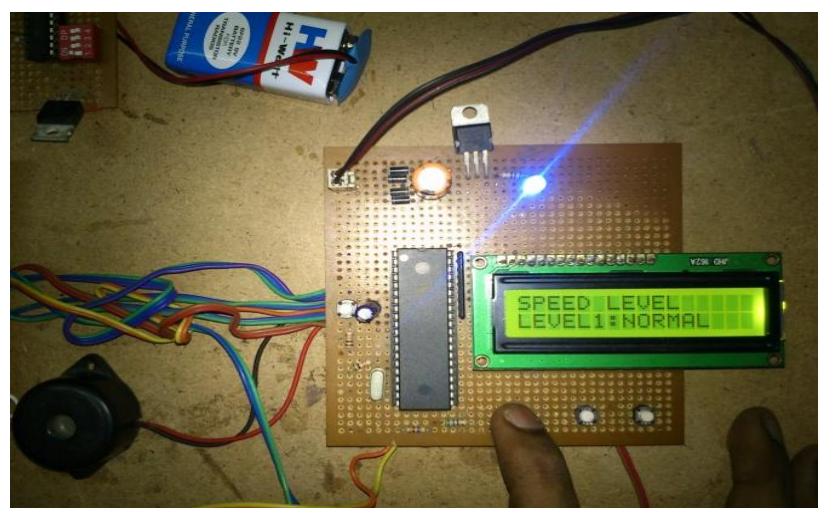

Figure 9: Display of Normal speed level when low speed is pressed by loco pilot.

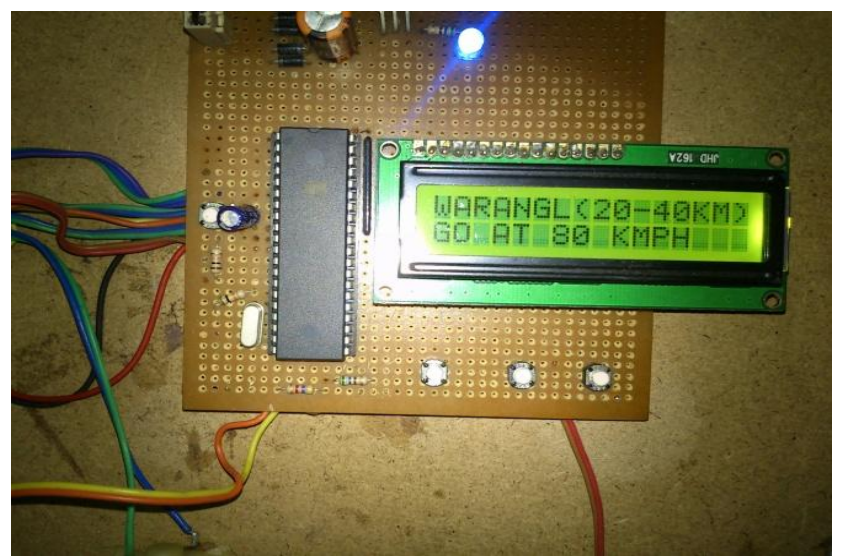

Figure 10: Display of Warangal station with speed level.

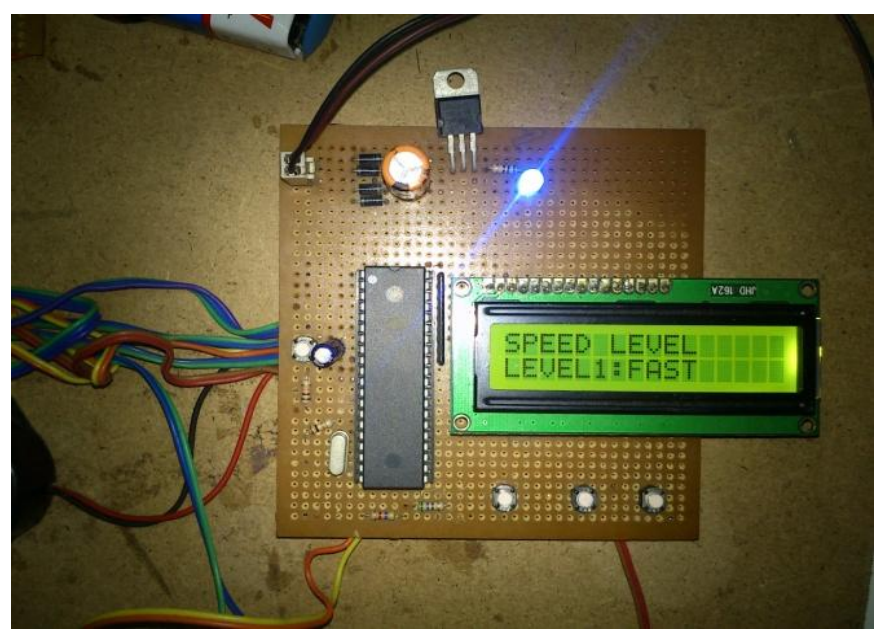

Figure 11: Display of Fast speed level when high speed is pressed by loco pilot.

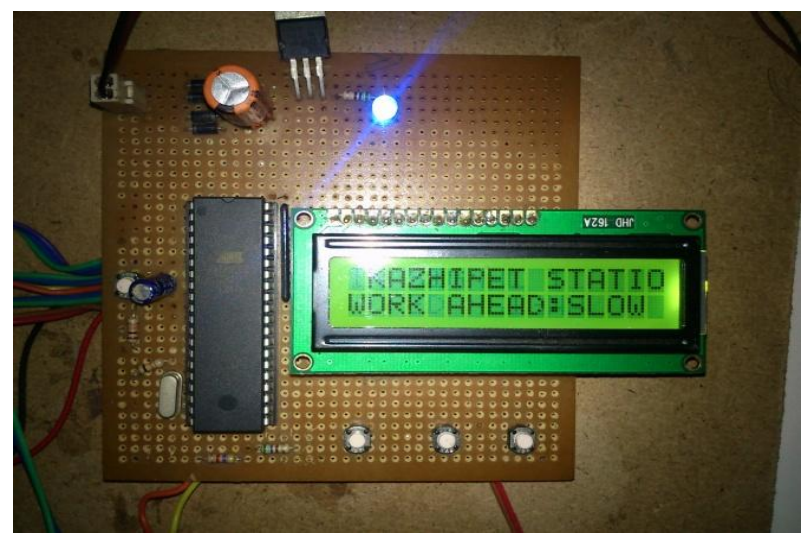

Figure 12: Display of kazhiphet station when a caution is given. 


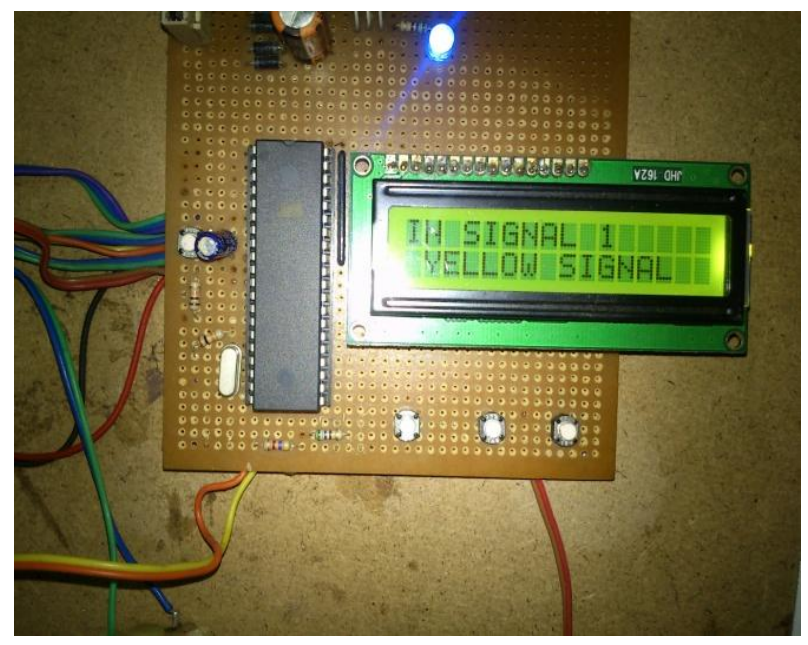

Figure 13: Display of yellow Signal at Signal post1.

\section{CONCLUSION}

Many people travel in trains and the number of people travelling is more when compared to any other like cars, buses etc. In this paper the Digital deliberation board and signaling system provides warning about the speed change and signals at the station which is digitally displayed on the LCD. So with the use of this device can ensure safety to passengers. The high priority is given to the lives of people. Hence this paper provides a feasible solution to reduce accidents due to misleading of train by loco pilot and due to invisibility of signals.

\section{ACKNOWLEDGEMENT}

I would like to thank our HOD - Dr. M. Kamaraju, G.Rama Krishna -assistant professor, ECE department. I also express my grateful thanks to principal-Dr.P.Nageswar Rao; Gudlavalleru engineering college. I would also thank V.Samson Deva Kumar, project manager, SCR.

\section{REFERENCES}

[1] Praveen Blessington1, *B.T.P.Madhav " Acoustic Controlled Robotic Vehicle", ISSN 2250-2459, Volume 2, Issue 4, April 2012.
[2] Dr.S.Bhargavi and Dr.B.R.Ramamurthy" Remote Sensing and Control of Various Electrical, Atmospheric Parameters in large Scale Industries", International Journal of Computer Trends and Technology- May to June Issue 2011.

[3] U. Jyothi Kameswari ,M. Satwik and A. Lokesh "A Design Model for Automatic Vehicle Speed Controller", International Journal of Computer Applications (0975 - 8887) Volume 35- No.9, December 2011.

[4] R.Kousalya, P.Musthafa and G.Murugesan “ An Intelligent Mobile Robot Navigation Technique Using RFID Technology",INTERNATIONAL JOURNAL OF ADVANCED ENGINEERING SCIENCES AND TECHNOLOGIES Vol No. 8, Issue No. 1, 065 - 074.

[5] Vardhman J. Sheth, Prasheel V and Suryawanshi "On the Design and Development of a Motion Control System using Accelerometer and RF Communication", International Journal of Engineering Research and Applications (IJERA) ISSN: 2248-9622 Vol. 2, Issue 2, Mar-Apr 2012, pp.486-489.

[6] P. Ajay Kumar Reddy , P.Dileep Kumar , K. Bhaskar reddy, and E.Venkataramana "BLACK BOX FOR VEHICLES", International Journal of Engineering Inventions ISSN: 2278-7461, Volume 1, Issue 7(October2012) PP: 06-12.

[7] Sheikh Shanawaz Mostafa, Md. Mahbub Hossian , Khondker Jahid Reza and Gazi Maniur Rashid," A Radio Based Intelligent Railway Grade Crossing System to Avoid Collision", IJCSI International Journal of Computer Science Issues, Vol. 7, Issue 6, November 2010 ISSN (Online): 1694-0814.

[8] Atul Kr. Dewangan, Meenu Gupta and and Pratibha Patel "Automation of Railway Gate Control Using Frequency Modulation Techniques", VSRD-IJEECE, Vol. 2 (6), 2012, 288-298. 